\title{
Ultralight conducting PEDOT:PSS/carbon nanotube aerogels doped with silver for thermoelectric materials
}

\author{
Xijing Sun, Yanhong Wei, Juanjuan Li, Jinghong Zhao, Lijuan Zhao* and Quan Li*
}

\begin{abstract}
A significant enhancement in the thermoelectric performance was observed for three-dimensional conducting aerogels, which were obtained from poly(3,4-ethylenedioxythiophene) : poly(4-styrenesulfonic) (PEDOT:PSS) and multiwalled carbon nanotubes (MWCNTs) suspensions by adding different concentrations of metallic silver (Ag). It was found that the electrical conductivity and Seebeck coefficient could be simultaneously increased with the unique structure. Moreover, the conducting aerogels have an ultralow thermal conductivity $(0.06 \mathrm{~W}$ $\mathbf{m}^{-1} \mathrm{~K}^{-1}$ ) and a large Brunauer-Emmett-Teller surface area $\left(228 \mathrm{~m}^{2} \mathrm{~g}^{-1}\right)$. The highest figure of merit $(z T)$ value in this study was $7.56 \times 10^{-3}$ at room temperature upon the addition of 33.32 wt.\% Ag. Although the $z T$ value was too low, our work may provide new insights into the design and development of the thermoelectric material for applications. Further investigation with PEDOT:PSS aerogels will be continued to get an economical, lightweight, and efficient polymer thermoelectric material.
\end{abstract}

Keywords: PEDOT:PSS, thermoelectric, carbon nanotube, silver, aerogel

\section{INTRODUCTION}

Most countries are now seeking new energy conversion materials, and one promising candidate is thermoelectric (TE) materials, which can convert waste heat into electricity [1]. Traditional TE materials are mainly based on inorganic materials such as bismuth-telluride (Bi-Te) and metal oxides [2,3]. However, commercially available inorganic TE materials have limited applications due to their instability, high cost, potential toxicity, and scarcity of some key elements. Meanwhile, most inorganic TE materials show their optimum performance at high temperatures, but a huge amount of waste heat is of low grade, i.e., the temperature below $200^{\circ} \mathrm{C}$, and these materials have a low energy conversion efficiency due to the small temperature difference $[4,5]$. In order to recover the low-temperature waste heat by the use of TE materials, conducting organic TE materials have become the ideal choice because of their low cost and processing convenience. Furthermore, organic TE materials have many other advantages such as a low energy consumption, stability in air, wide sources, environmental friendliness, and easy synthesis and processing [6,7].

For TE materials, the ability to convert energy between heat and electricity depends on the figure of merit, $z T=$ $S^{2} \sigma T / \kappa$, where $S, \sigma, \kappa$, and $T$ are the Seebeck coefficient, electrical conductivity, thermal conductivity, and absolute temperature, respectively. A combination of a high $\sigma$ and $S$ with a low $\kappa$ is a key factor to obtain a high $z T$ value. The conducting polymer has a low thermal conductivity, which is about $1-3$ orders of magnitude lower than those of inorganic materials [8-11]. Organic TE materials including polyaniline, polyacetylene, polythiophene, and polypyrrole have been intensively evaluated, and the past years have also witnessed their remarkable developments [12-15]. However, it is found that the $z T$ values of organic TE materials are still too low to be satisfactory, which imposes a great challenge for conducting polymers to be used as TE materials. Nevertheless, a breakthrough was achieved by controlling the doping and oxidation level of poly(3,4-ethylenedioxythiophene) (PEDOT). For example, PEDOT composites generate $z T=0.42$ at room temperature, which is comparable to those of some traditional inorganic materials [6,16-20]. Organic/inorganic hybridization is another promising way to improve the thermoelectric performance of polymers [21-23]. Zhang et al. [24] reported that the template-directed in situ polymerization preparation of nanocomposites of

College of Chemistry and Materials Science, Sichuan Normal University, Chengdu 610068, China

*Corresponding authors (emails: lijuan_zhao@sicnu.edu.cn (Zhao L); Liquan6688@163.com (Li Q)) 
PEDOT:poly(4-styrenesulfonic) (PSS) coated with multiwalled carbon nanotubes (MWCNTs) can enhance the thermoelectric properties. There is a strong interaction between PEDOT:PSS and MWCNTs, which can lead to the formation of interconnected electrical conducting channels to improve the electrical conductivity. Zhang et al. found that a post-treatment can remove part of the insulating PSS from the surface of the PEDOT:PSS/reduced graphene oxide ( $\mathrm{r}-\mathrm{GO}$ ) composite film, resulting in a significant conductivity enhancement of the composites because the addition of $\mathrm{r}-\mathrm{GO}$ can trigger a change in the PEDOT main chain from a benzene structure to a quinoid structure, which can achieve the transfer of electric charge [25]. Compared with traditional inorganic TE materials, the electrical conductivity and Seebeck coefficients of PEDOT:PSS composites are not very high, and the $z T$ values are still low $\left(10^{-3}\right.$ to $\left.10^{-1}\right)$ [26-28]. However, the thermal conductivity is in the range of $0.1-0.4 \mathrm{~W} \mathrm{~m}^{-1} \mathrm{~K}^{-1}$, which is much lower than those of traditional inorganic TE materials $[7,29,30]$. Therefore, the main challenge for organic polymer TE materials is to obtain a large Seebeck coefficient and electrical conductivity simultaneously while keeping a low thermal conductivity.

Aerogels are ultralight nanoporous materials with large surface areas and a high porosity, which allow them to have potential applications in electronic devices, catalysis, and detectors [31-33]. In this work, we report a new nanocomposite aerogel based on PEDOT:PSS, MWCNTs, and Ag (PCA). The choice of the latter two components is motivated by the fact that MWCNTs are expected to construct a three-dimensional (3D) solid skeleton, and the excellent bulk electrical conductivity of $\mathrm{Ag}$ is introduced into PEDOT:PSS system to enhance the electrical conductivity [34]. The results show that PCA aerogels possess a large specific surface area, electrical conductivity, and Seebeck coefficient simultaneously, while the thermal conductivity is nearly one order of magnitude lower compared with that of pure PEDOT:PSS $\left(0.348 \pm 0.01 \mathrm{~W} \mathrm{~m}^{-1} \mathrm{~K}^{-1}\right)$ [7], and the $z T$ value is greatly enhanced with various $\mathrm{Ag}$ contents.

\section{EXPERIMENTAL SECTION}

\section{Materials}

A PEDOT:PSS aqueous solution (Clevios PH 1000) was purchased from H. C. Stark (Germany). The concentration of PEDOT:PSS is about $1.3 \mathrm{wt} . \%$, and the weight ratio of PSS to PEDOT is 2.5. MWCNTs were offered by SkySpring Nanomaterials, Inc. (Belgium). All experimental chemicals were used without further purification, and other chemicals were purchased from Chengdu Kelong Company (China).

\section{Preparation of PCA aerogels}

Different amounts of Ag with $0.065 \mathrm{~g}$ of MWCNTs were mixed in $5 \mathrm{~g}$ of the PEDOT:PSS solution by ultrasonication $\left(20-30^{\circ} \mathrm{C}, 100 \mathrm{~W}\right.$, and $\left.2 \mathrm{~h}\right)$. The resulting PCA suspensions were quenched with liquid nitrogen and then freeze-dried for $24 \mathrm{~h}$ to obtain the PCA aerogels. The relative Ag contents would be 8.89, 16.67, 20.87, 25.93, 28.81, 33.32, and 37.28 wt.\% in the PCA aerogels. Moreover, a PEDOT:PSS/MWCNTs (PC) aerogel was also prepared for comparison. The preparation process of the PCA aerogels is illustrated in Fig. 1.

\section{Characterization}

The microstructures of the PCA and PC aerogels were examined by scanning electron microscopy (SEM, Quanta250). Nitrogen sorption measurements were performed with a TriStar Micromeritics instrument to obtain pore properties such as the Brunauer-Emmett-Teller (BET) specific surface area.

The thermal conductivity $(k)$ was measured by a transient plane source method using a Hot Disk 2500-OT analyzer. A standard four-probe method was used for the electrical conductivity $(\sigma)$ measurement at room temperature on the RTS-8 equipment (Guangzhou Four-probe Technology Company, China). The current transmitted through the sample during measurement was $10 \mathrm{~mA}$. The Seebeck coefficient $(S)$ was measured by placing the sample between two copper cylinders attached to two Peltier modules, with one for heating and another for cooling. It would generate the temperature gradient $(D T)$ across the sample and induce a thermal voltage. $D T$ was accurately measured by two miniature thermocouples, and the induced voltage gradient $(D V)$ was measured using the voltage probes. Thus, the Seebeck coefficient $(S)$ was determined from the slope of the linear relationship between the thermoelectric motive force and the temperature difference between two points on the aerogels, which was expressed as $S=D V / D T$. The figure of merit at room temperature was calculated by $z T=$ $S^{2} T \sigma / k$.

\section{RESULTS AND DISCUSSION}

The microstructures of the PC and PCA aerogels were examined with SEM. The PC aerogel has a 3D porous network with interconnected particles and continuously open macropores (as shown in Fig. 2a). More interestingly, most MWCNTs are embedded in PEDOT, showing a strong interaction between the MWCNTs and PEDOT, as indicated 


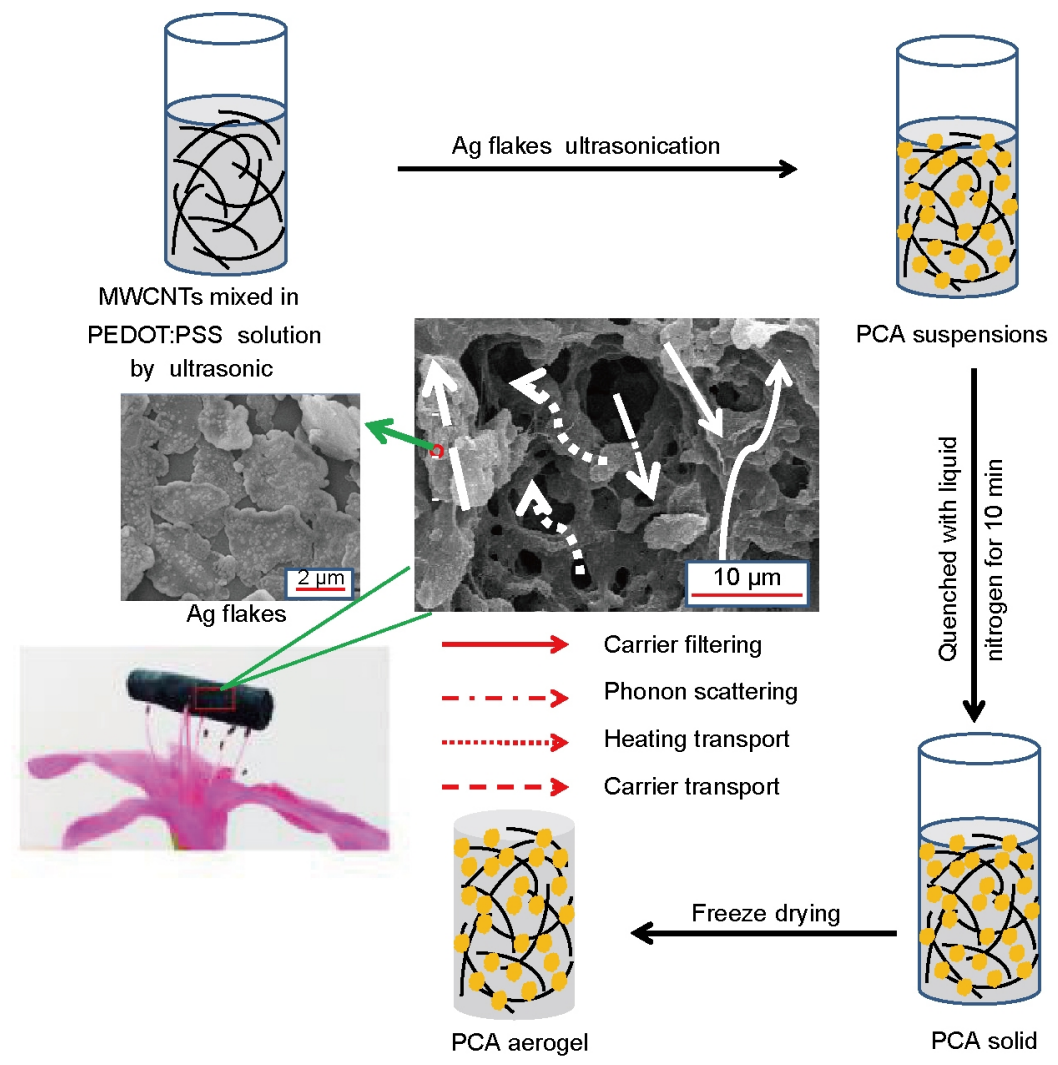

Figure 1 Illustration of the process for the preparation of the PCA aerogels.
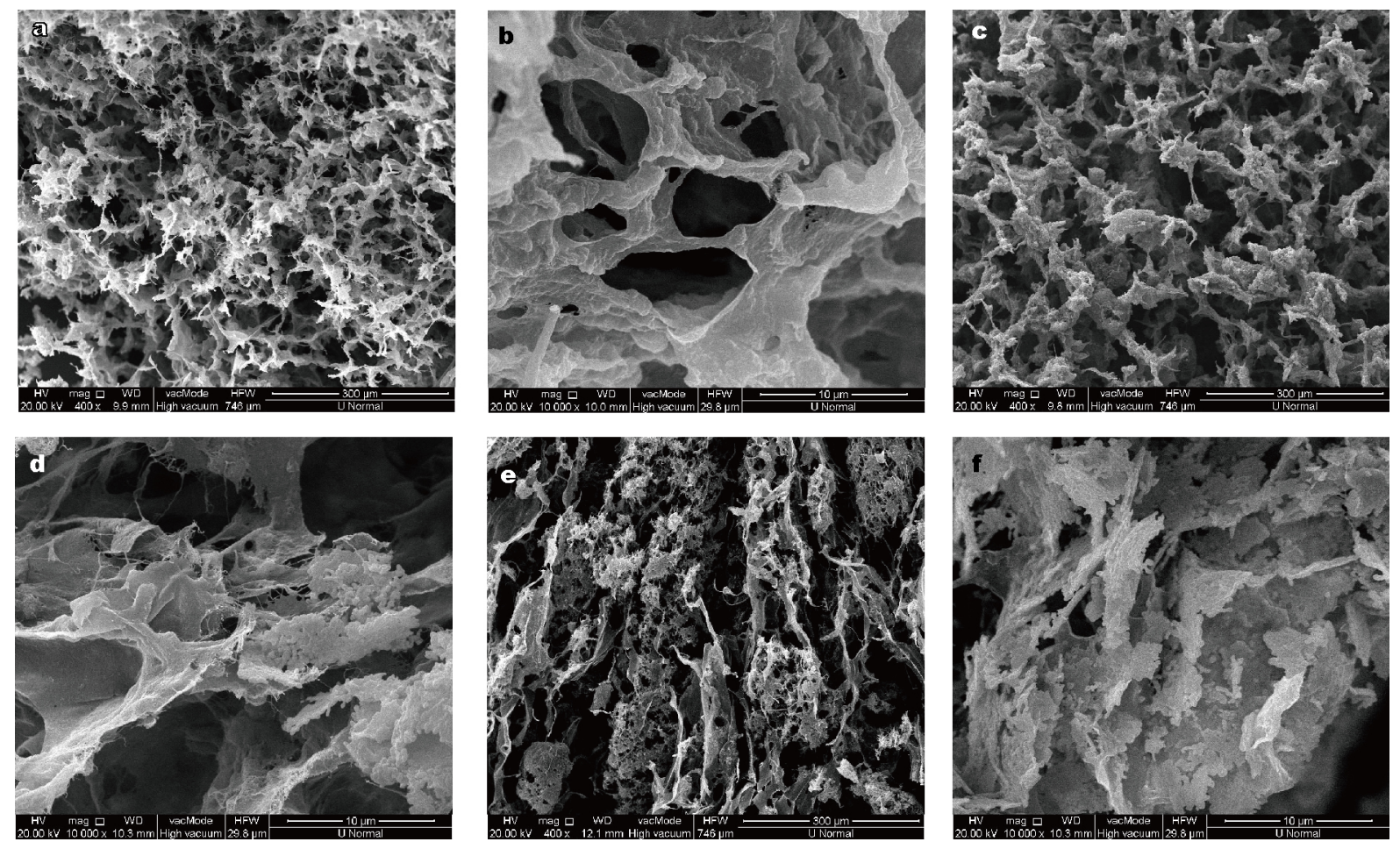

Figure 2 SEM images of the PC aerogel (a, b) and the PCA aerogels with Ag contents of 20.87 wt.\% (c, d) and 37.28 wt.\% (e, f). 

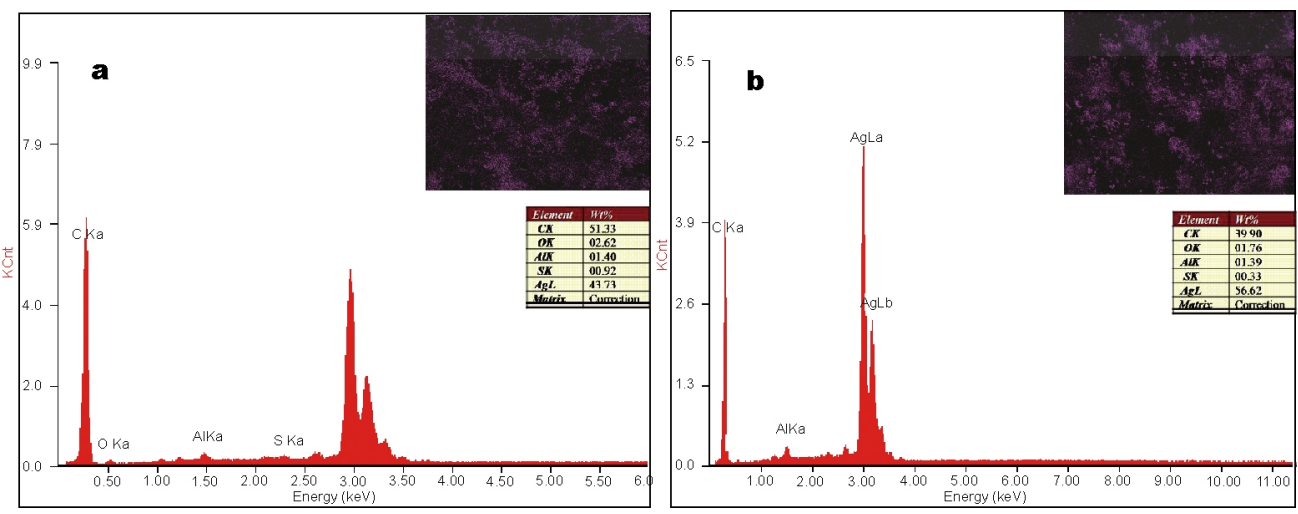

Figure 3 Energy dispersive X-ray analysis and the mapping images (insets) for the samples with Ag contents of 20.87 wt.\% (a) and 37.28 wt.\% (b).

in Fig. 2b. Meanwhile, the compacted connection would lead to the carrier mobility and generate the electrical conductivity. As illustrated in Fig. 2c-f, the PCA aerogels also have porous network structures that are similar to that of the PC aerogel, and the network structures become denser with the presence of $\mathrm{Ag}$, which is over $20.87 \mathrm{wt} . \%$ in the matrix. The interconnected structures can benefit the improvement in the electrical conductivity and result in a reduction in the thermal conductivity. However, normally defects exist in the large porous structure, which easily lead to a discontinuous phase and decrease the electrical conductivity in PCA aerogels. Moreover, the network structure becomes agglomerated when the Ag contents are overloaded, as demonstrated in Fig. 2e, which may result in an enhancement in the thermal conductivity because the more compacted connection would reduce the phonon scattering and improve the heat conduction. The mapping images of samples with 20.87 and 37.28 wt.\% Ag contents are shown in Fig. 3a, b. It is demonstrated that the actual Ag contents in the composites are 21.16 and 37.09 wt.\%, respectively, which are consistent with our experiments.

A large specific surface area and a low weight are two typical characteristics of aerogels $[35,36]$. The evolution of the BET surface area of PCA aerogels with different Ag contents is shown in Fig. 4. After introducing MWCNTs to the PEDOT:PSS solution, the MWCNTs disperse in the solution as a certain molecular precursor, and this precursor builds up a 3D porous structure, where the MWCNTs will be finally immobilized by a cross-linked organic binder of polymer, which forms the junctions between the adjacent MWCNT bundles. As presented in Fig. 4, the pure PC aerogel has a BET surface area of $143 \mathrm{~m}^{2} \mathrm{~g}^{-1}$. With the incorporation of $25.93 \mathrm{wt} . \% \mathrm{Ag}$ in the PCA aerogels, the BET surface area increases significantly to $228 \mathrm{~m}^{2} \mathrm{~g}^{-1}$, suggesting that the hybridized structures composed of Ag flakes are

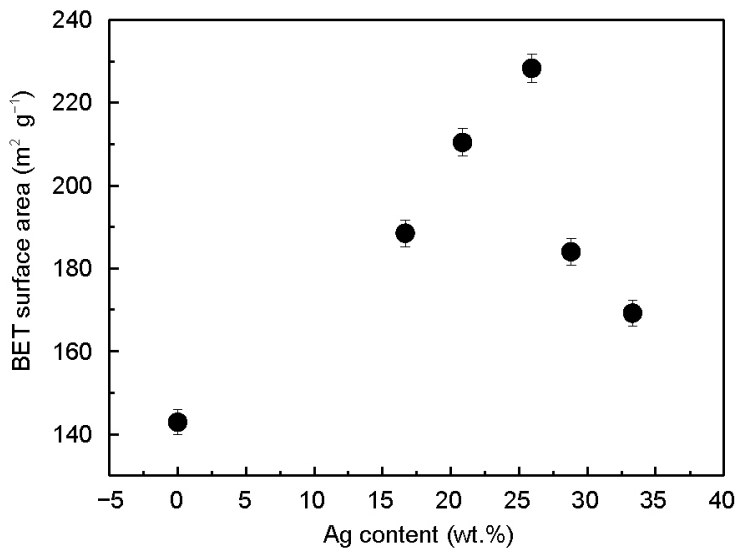

Figure 4 BET surface area of the PCA aerogels with different weight fractions of $\mathrm{Ag}$.

beneficial to the porous structure. However, further additions of Ag flakes to the PCA aerogels lead to a decreased BET surface area due to the denser porous structure, as shown in the SEM images. In the PCA aerogels with 37.28 wt.\% Ag, the BET surface area shows a remarkable decrease from 228 to $169 \mathrm{~m}^{2} \mathrm{~g}^{-1}$. The reason is that the $\mathrm{Ag}$ flakes cannot be effectively dispersed between the organic binder at a higher Ag weight fraction, which prevents the formation of micropores in aerogels and results in a decrease in the BET surface area.

According to $z T=S^{2} \sigma T / \kappa$, excellent TE materials depend on a high Seebeck coefficient and electrical conductivity. Meanwhile, in order to build up a high temperature difference, it is necessary for TE materials to have a low thermal conductivity.

Fig. 5a shows the electrical conductivity values of PCA aerogels with different weight fractions of $\mathrm{Ag}$ at room temperature, and the electrical conductivity of the aerogels effectively improved after adding Ag flakes. Particularly, the 

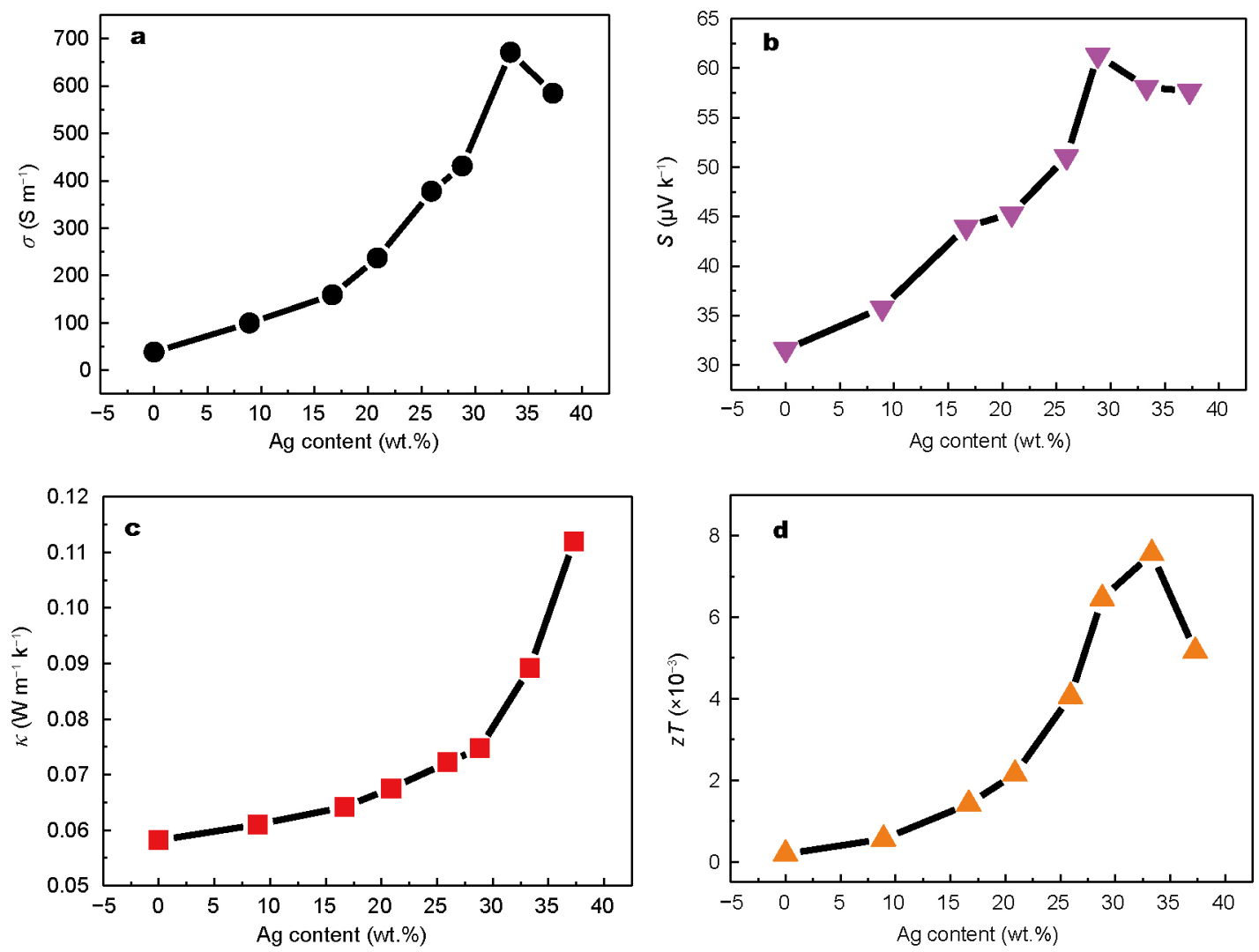

Figure 5 Electrical conductivity (a), Seebeck coefficient (b), thermal conductivity (c) and the $z T$ values (d) of the PCA aerogels with different weight fractions of $\mathrm{Ag}$ at room temperature.

electrical conductivity of the PC aerogel is $38.1 \mathrm{~S} \mathrm{~m}^{-1}$ because the PEDOT and MWCNT sheets form an intact 3D network with tight junctions, which is more effective for electron transport than a physically-bonded network [37]. Upon the addition of $25.93 \mathrm{wt} \% \mathrm{Ag}$, the electrical conductivity of the PCA aerogel increases to $377.4 \mathrm{~S}$ $\mathrm{m}^{-1}$, which is nearly 10 times higher than that of the PC aerogel. The reason for the improvement is that Ag flakes and MWCNTs create better electrically contacted bridges between nanoparticles. A conductivity of $671.1 \mathrm{~S} \mathrm{~m}^{-1}$ is achieved with $33.32 \mathrm{wt} . \%$ Ag loading, indicating that the samples with higher Ag contents exhibit a higher electrical conductivity at room temperature. However, the electrical conductivity exhibits a slight decrease with a further increase in the $\mathrm{Ag}$ content because it is difficult to disperse Ag flakes in a PC suspension at a high Ag weight fraction, which has a negative effect on the integrity of the network.

Despite the great increase in the electrical conductivity by adding Ag, the Seebeck coefficients of PCA aerogels as a function of the $\mathrm{Ag}$ content range from 30 to $70 \mu \mathrm{V} \mathrm{K} \mathrm{K}^{-1}$, as shown in Fig. 5b. These Seebeck coefficient values are higher than those of pure PEDOT:PSS $\left(\sim 20 \mu \mathrm{V} \mathrm{K}^{-1}\right)$ and PC composites $\left(15-30 \mu V K^{-1}\right)[29,35,38]$. The Seebeck coefficient of the PC aerogel is measured to be $31.6 \mu \mathrm{V} \mathrm{K}^{-1}$, while it is prominent that the Seebeck coefficient increases upon the addition of Ag. A significant enhancement of $61.3 \mu \mathrm{V}$ $\mathrm{K}^{-1}$ is achieved when the $\mathrm{Ag}$ content is $28.81 \mathrm{wt} . \%$, but the further addition of $\mathrm{Ag}$ oppositely suppresses the Seebeck coefficient slightly. Therefore, the PCA aerogels are more efficient in converting the temperature gradient into a voltage than the PC aerogels, which maybe originates probably from an energy-filtering effect [39]. It is very difficult to understand the simultaneous increases in the Seebeck coefficient and electrical conductivity in the porous structure. However, it is interesting that the results of our experiments show that the electrical conductivity and Seebeck coefficient increase simultaneously in the porous structure. This is because there are abundant interfaces among the MWCNTs, Ag flakes, and PEDOT:PSS, and the work functions of these three components are different. Low-energy carriers can be strongly scattered by an appropriately engineered potential barrier at the interface, which allows carriers with a higher energy to pass through, thereby increasing the mean carrier energy in the flow, i.e., the Seebeck 
coefficient. However, the interface in the PCA aerogel decreases with the further addition of Ag, so the energy-filtering effect is weakened and accompanied by a reduction in the Seebeck coefficient simultaneously. Actually, the energy-filtering effect has already been successfully used to interpret the increased Seebeck coefficient in many other hybrid composites [40,41].

Besides the large electrical conductivity and Seebeck coefficients, a low thermal conductivity is also crucial for TE materials. It is well-known that the thermal conductivity is mainly divided into the electrical thermal conductivity $\left(\kappa_{\mathrm{e}}\right)$ and the lattice thermal conductivity $\left(\kappa_{\mathrm{l}}\right): \kappa=\kappa_{\mathrm{e}}+\kappa_{\mathrm{l}}$ [23]. Reducing $\kappa_{1}$ is one of the effective ways to improve the $z T$ value. Although MWCNTs have an ultrahigh thermal conductivity $\left(3075 \mathrm{~W} \mathrm{~m}^{-1} \mathrm{~K}^{-1}\right)$ at room temperature due to efficient heat transfer by lattice vibrations [42], the PC aerogel keeps a low thermal conductivity of around 0.05 $\mathrm{W} \mathrm{m} \mathrm{m}^{-1} \mathrm{~K}^{-1}$ in Fig. $5 \mathrm{c}$ because the unique network structure can effectively scatter phonons, resulting in a reduction in the lattice thermal conductivity without having to compromise the carrier mobility values. However, with the addition of Ag, the thermal conductivity increases slightly. It is exciting that the thermal conductivity of the PCA aerogels is in the range of 0.06 to $0.11 \mathrm{~W} \mathrm{~m}^{-1} \mathrm{~K}^{-1}$ at room temperature, which is much smaller than the thermal conductivity of many reported organic polymer TE materials [43-45]. The gaseous, radiative, and convective thermal conductivities also play important parts in the thermal conductivity of aerogel materials [46,47], which results in the ultralow thermal conductivity of the PCA aerogels.

With the combined effects of the Seebeck coefficient, electrical conductivity, and thermal conductivity, the highest $z T$ value of $7.56 \times 10^{-3}$ is generated at room temperature upon the addition of a $\mathrm{Ag}$ content of $33.32 \mathrm{wt} . \%$, as it is displayed in Fig. 5d. Compared with that of the pure PC aerogel, the $z T$ value is nearly one order of magnitude higher. Although the $z T$ value is still low for practical applications, this work explores the basic TE properties of PCA aerogels.

\section{CONCLUSIONS}

In this work, a series of conducting aerogels based on PEDOT:PSS, MWCNTs, and Ag flakes were successfully prepared; meanwhile, the relationships between their thermoelectric properties (Seebeck coefficient, electrical conductivity, and thermal conductivity) and microstructure were investigated. This type of conducting aerogel possesses a large specific surface area with a BET surface area up to 228 $\mathrm{m}^{2} \mathrm{~g}^{-1}$. The incorporation of MWCNTs and Ag flakes si- multaneously benefits in building the 3D porous network structure and increases the electrical conductivity and Seebeck coefficient simultaneously, while the thermal conductivity of the conducting aerogels remains at a very low level of 0.06 to $0.11 \mathrm{~W} \mathrm{~m}^{-1} \mathrm{~K}^{-1}$ at room temperature. Therefore, the results of this study demonstrate that the three TE parameters are successfully decoupled in the new conducting aerogels, which significantly improves the $z T$ value at room temperature. Furthermore, by taking advantage of its easy processing and environmentally friendly nature, the conducting PC aerogels doped with Ag have potential applications in thermoelectric refrigeration and microgeneration areas.

Received 22 September 2016; accepted 27 December 2016; published online 17 January 2017

1 Zhao LD, Lo SH, Zhang Y, et al. Ultralow thermal conductivity and high thermoelectric figure of merit in SnSe crystals. Nature, 2014, 508: $373-377$

2 Sparks TD, Gurlo A, Clarke DR. Enhanced n-type thermopower in distortion-free $\mathrm{LiMn}_{2} \mathrm{O}_{4}$. J Mater Chem, 2012, 22: 4631-4636

3 Zhang JS, Yang JY, Feng SL, et al. Preparation and thermoelectric properties of p-type $\mathrm{Bi}_{0.52} \mathrm{Sb}_{1.48} \mathrm{Te}_{3}+3 \%$ Te thin films. Chin Sci Bull, 2012, 57: 4220-4224

4 Wei Q, Mukaida M, Kirihara K, et al. Recent progress on PEDOTbased thermoelectric materials. Materials, 2015, 8: 732-750

5 Toshima N, Ichikawa S. Conducting polymers and their hybrids as organic thermoelectric materials. J Elec Materi, 2015, 44: 384-390

6 Sun K, Zhang S, Li P, et al. Review on application of PEDOTs and PEDOT:PSS in energy conversion and storage devices. J Mater SciMater Electron, 2015, 26: 4438-4462

7 Park H, Lee SH, Kim FS, et al. Enhanced thermoelectric properties of PEDOT:PSS nanofilms by a chemical dedoping process. J Mater Chem A, 2014, 2: 6532-6539

8 Du Y, Shen SZ, Cai K, et al. Research progress on polymer-inorganic thermoelectric nanocomposite materials. Prog Polymer Sci, 2012, 37: 820-841

9 Zhou Y, Wang L, Zhang H, et al. Enhanced high thermal conductivity and low permittivity of polyimide based composites by core-shell Ag@SiO $\mathrm{O}_{2}$ nanoparticle fillers. Appl Phys Lett, 2012, 101: 012903

10 Han Z, Fina A. Thermal conductivity of carbon nanotubes and their polymer nanocomposites: a review. Prog Polymer Sci, 2011, 36: 914-944

11 Dubey N, Leclerc M. Conducting polymers: efficient thermoelectric materials. J Polym Sci B Polym Phys, 2011, 49: 467-475

12 Islam R, Chan-Yu-King R, Brun JF, et al. Transport and thermoelectric properties of polyaniline/reduced graphene oxide nanocomposites. Nanotechnology, 2014, 25: 475705

13 Zuzok R, Kaiser AB, Pukacki W, et al. Thermoelectric power and conductivity of iodine-doped "new" polyacetylene. J Chem Phys, 1991, 95: 1270-1275

14 Wang L, Jia X, Wang D, et al. Preparation and thermoelectric properties of polythiophene/multiwalled carbon nanotube composites. Synth Met, 2013, 181: 79-85

15 Wang J, Cai K, Shen S, et al. Preparation and thermoelectric properties of multi-walled carbon nanotubes/polypyrrole composites. Synth Met, 2014, 195: 132-136 
16 Chen HY, Shen HP, Wu CH, et al. Core-shell composite latexes derived from PEDOT:PSS dispersion and the preparation of conductive, flexible and transparent films. J Mater Chem C, 2013, 1: 5351-5358

17 Han S, Feng Y, Chen G, et al. Facile preparation of composites composed of high performance thermoplastic and difficult-to-process functional polymer. RSC Adv, 2014, 4: 31874-31878

18 Park T, Park C, Kim B, et al. Flexible PEDOT electrodes with large thermoelectric power factors to generate electricity by the touch of fingertips. Energ Environ Sci, 2013, 6: 788-792

19 Mengistie DA, Chen CH, Boopathi KM, et al. Enhanced thermoelectric performance of PEDOT:PSS flexible bulky papers by treatment with secondary dopants. ACS Appl Mater Interfaces, 2015, 7: 94-100

20 Kim GH, Shao L, Zhang K, et al. Engineered doping of organic semiconductors for enhanced thermoelectric efficiency. Nat Mater, 2013, 12: 719-723

$21 \mathrm{Ju} \mathrm{H}, \mathrm{Kim}$ J. Chemically exfoliated SnSe nanosheets and their SnSe/poly(3, 4-ethylenedioxythiophene) : poly(styrenesulfonate) composite films for polymer based thermoelectric applications. ACS Nano, 2016, 10: 5730-5739

22 Du Y, Shen SZ, Yang WD, et al. Preparation and characterization of multiwalled carbon nanotube/poly(3-hexylthiophene) thermoelectric composite materials. Synth Met, 2012, 162: 375-380

23 Zhao L, Zhao J, Sun X, et al. Enhanced thermoelectric properties of hybridized conducting aerogels based on carbon nanotubes and pyrolyzed resorcinol-formaldehyde resin. Synth Met, 2015, 205: 64-69

24 Zhang Z, Chen G, Wang H, et al. Template-directed in situ polymerization preparation of nanocomposites of PEDOT:PSS-coated multi-walled carbon nanotubes with enhanced thermoelectric property. Chem Asian J, 2015, 10: 149-153

25 Zhang M, Yuan W, Yao B, et al. Solution-processed PEDOT:PSS/graphene composites as the electrocatalyst for oxygen reduction reaction. ACS Appl Mater Interfaces, 2014, 6: 3587-3593

26 Kong FF, Liu CC, Xu JK, et al. Simultaneous enhancement of electrical conductivity and Seebeck coefficient of poly(3,4-ethylenedioxythiophene):poly(styrenesulfonate) films treated with urea. Chin Phys Lett, 2011, 28: 037201

27 Culebras M, Gómez CM, Cantarero A. Enhanced thermoelectric performance of PEDOT with different counter-ions optimized by chemical reduction. J Mater Chem A, 2014, 2: 10109-10115

28 Toshima N, Jiravanichanun N. Improvement of thermoelectric properties of PEDOT/PSS films by addition of gold nanoparticles: enhancement of Seebeck coefficient. J Elec Materi, 2013, 42: 1882-1887

29 Kim D, Kim Y, Choi K, et al. Improved thermoelectric behavior of nanotube-filled polymer composites with poly(3,4-ethylenedioxythiophene):poly(styrenesulfonate). ACS Nano, 2010, 4: 513-523

30 Jiang FX, Xu JK, Lu BY, et al. Thermoelectric performance of poly(3,4-ethylenedioxythiophene) : poly(styrenesulfonate). Chin Phys Lett, 2008, 25: 2202-2205

31 Qian Y, Ismail IM, Stein A. Ultralight, high-surface-area, multifunctional graphene-based aerogels from self-assembly of graphene oxide and resol. Carbon, 2014, 68: 221-231

32 Zhao L, Sun X, Lei Z, et al. Thermoelectric behavior of aerogels based on graphene and multi-walled carbon nanotube nanocomposites. Composites Part B-Eng, 2015, 83: 317-322

33 Lázár I, Bereczki HF, Manó S, et al. Synthesis and study of new functionalized silica aerogel poly(methyl methacrylate) composites for biomedical use. Polym Compos, 2015, 36: 348-358

34 Roussel F, King RCY, Kuriakose M, et al. Electrical and thermal transport properties of polyaniline/silver composites and their use as thermoelectric materials. Synth Met, 2015, 199: 196-204

35 Chang KC, Jeng MS, Yang CC, et al. The thermoelectric performance of poly(3,4-ethylenedi oxythiophene)/poly(4-styrenesulfonate) thin films. J Elec Materi, 2009, 38: 1182-1188

36 Lei Z, Yan Y, Feng J, et al. Enhanced power factor within graphene hybridized carbon aerogels. RSC Adv, 2015, 5: 25650-25656

37 Gutiérrez MC, Rubio F, del Monte F. Resorcinol-formaldehyde polycondensation in deep eutectic solvents for the preparation of carbons and carbon-carbon nanotube composites. Chem Mater, 2010, 22: 2711-2719

38 Kim JY, Jung JH, Lee DE, et al. Enhancement of electrical conductivity of poly(3,4-ethylenedioxythiophene)/poly(4-styrenesulfonate) by a change of solvents. Synth Met, 2002, 126: 311-316

39 He M, Ge J, Lin Z, et al. Thermopower enhancement in conducting polymer nanocomposites via carrier energy scattering at the organic-inorganic semiconductor interface. Energ Environ Sci, 2012, 5: 8351-8358

40 Ko DK, Kang Y, Murray CB. Enhanced thermopower via carrier energy filtering in solution-processable $\mathrm{Pt}-\mathrm{Sb}_{2} \mathrm{Te}_{3}$ nanocomposites. Nano Lett, 2011, 11: 2841-2844

41 Martin J, Wang L, Chen L, et al. Enhanced Seebeck coefficient through energy-barrier scattering in $\mathrm{PbTe}$ nanocomposites. Phys Rev B, 2009, 79: 115311

42 Kim P, Shi L, Majumdar A, et al. Thermal transport measurements of individual multiwalled nanotubes. Phys Rev Lett, 2001, 87: 215502

43 Chang WB, Fang H, Liu J, et al. Electrochemical effects in thermoelectric polymers. ACS Macro Lett, 2016, 5: 455-459

44 Liu J, Wang X, Li D, et al. Thermal conductivity and elastic constants of PEDOT:PSS with high electrical conductivity. Macromolecules, 2015, 48: 585-591

45 Song $\mathrm{H}$, Liu C, Zhu H, et al. Improved thermoelectric performance of free-standing PEDOT:PSS/ $\mathrm{Bi}_{2} \mathrm{Te}_{3}$ films with low thermal conductivity. J Elec Materi, 2013, 42: 1268-1274

46 Hrubesh LW, Pekala RW. Thermal properties of organic and inorganic aerogels. J Mater Res, 1994, 9: 731-738

47 Lee OJ, Lee KH, Jin Yim T, et al. Determination of mesopore size of aerogels from thermal conductivity measurements. J Non-Crystalline Solids, 2002, 298: 287-292

Acknowledgments This work was supported by the National Natural Science Foundation of China (51303116).

Author contributions Zhao L conceived the post-fabrication tuning of random modes and contributed to the theoretical analysis; Sun X designed and engineered the samples; Sun X, Wei Y, Li J and Zhao L performed the experiments; Sun X and Zhao L performed the data analysis; Sun X wrote the paper with support from Zhao L and Li Q. All authors contributed to the general discussion.

Conflict of interest The authors declare that they have no conflict of interest. 

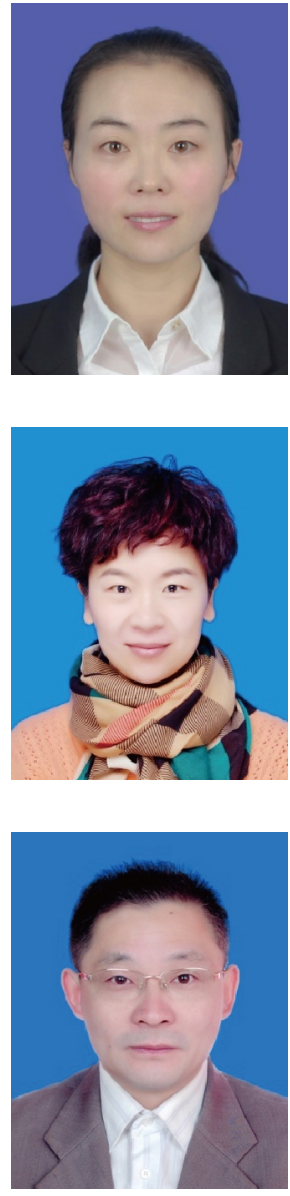

Xijng Sun is a master student of the College of Chemistry and Materials Science, Sichuan Normal University. She joined Prof. Lijuan Zhao's group in 2014 and her current research interests include the preparation and properties of thermoelectric materials.
Lijuan Zhao is a professor of chemistry at the College of Chemistry and Materials Science, Sichuan Normal University. She received his $\mathrm{PhD}$ degree in materials science from Sichuan University in 2009, followed by a period of postdoctoral research at Xinjiang Blue Ridge Tunhe Chemical Industry Joint Stock Co, Ltd. Her research interests include the structure performance study of functional materials; synthesis, characterization, and self-assembly of nanomaterials.
Quan Li is a professor of chemistry at the College of Chemistry and Materials Science, Sichuan Normal University. He received his $\mathrm{PhD}$ degree in atomic and molecular physics from Sichuan University in 2001. His research interests include the preparation and application study of materials.

\section{银掺杂PEDOT: PSS/碳纳米管超轻导电气凝胶热电材料}

孙希静, 魏燕红, 李娟娟, 赵敬红, 赵丽娟*, 李权*

摘要 本文以导电高分子PEDOT:PSS、多壁碳纳米管(MWCNTs)、银纳米片 (Ag)为原料制备了导电复合气凝胶. 研究发现, 该材料具有特 殊的3D网络结构, 并且该结构的存在有利于复合材料电导率和Seebeck系数同时提高, 而热导率保持较低水平. 室温下复合材料热导率低至 $0.06 \mathrm{~W} \mathrm{~m}^{-1} \mathrm{k}^{-1}$, 比表面积高达 $228 \mathrm{~m}^{2} \mathrm{~g}^{-1}$. 当 $\mathrm{Ag}$ 含量为 $33.32 \%$ 时, 该气凝胶热电材料室温下 $z T$ 值最高为 $7.56 \times 10^{-3}$. 虽然该 $z T$ 值仍较低, 尚不能 用于实际生产, 但本研究为热电材料的设计和开发利用提供了新的设计方法. 下一步工作将立足于PEDOT:PSS气凝胶制备经济、轻质、高 效的聚合物热电材料. 